www.jmscr.igmpublication.org

Impact Factor (SJIF): 6.379

Index Copernicus Value: 79.54

ISSN (e)-2347-176x ISSN (p) 2455-0450

crossrefDOI: https://dx.doi.org/10.18535/jmscr/v6i9.38

Journal Of Medical Science And Clinical Research

IGM Publication

An Official Publication of IGM Publication

\title{
Ocular Morbidity among Tribal School Children in Siliguri Sub-Division of Darjeeling District: A Cross-Sectional Study
}

\author{
Authors \\ Dr Rupanjli Lakra ${ }^{1}$, Dr Malabika Debbarma ${ }^{1}$, Dr Louis Tirkey ${ }^{2}$ \\ ${ }^{1}$ Assistant Professor, Department of Ophthalmology, North Bengal Medical College, West Bengal \\ ${ }^{2}$ Assistant Professor, Community Medicine, North Bengal Medical College, West Bengal \\ Corresponding Author \\ Dr Louis Tirkey \\ Assistant Professor, Community Medicine, North Bengal Medical College \& Hospital \\ P.O. Sushrutnagar, West Bengal, India, Pin: 734012 \\ Email: louistirkey@gmail.com, Mobile: 9434234599
}

\begin{abstract}
Introduction: Vision is the most important special sense in human being. Normal vision is essential for normal physical, mental, psychological development and education. Early detection and treatment of ocular morbidity is an easy way to improve child health and development.

Objectives: To estimate the prevalence of ocular morbidity among Tribal school children aged 5 - 15 years and socio-demographic factors related to it.

Materials and Methods: A school-based observational study with cross-sectional design was adopted to examine Tribal school children aged 5-15 years in randomly selected rural schools of Phansidewa \& Naxalbari blocks of Siliguri sub-division in Darjeeling district from April - July 2018 with a sample size of 180. Interpretation and analysis of the data was done using IBM SPSS version 20.

Results: A total of 180 Tribal students 86(47.8\%) males and 94(52.2\%) females were examined. The overall Prevalence of ocular morbidity was high (51.7\%). Allergic conjunctivitis (38.7\%) was the major cause of ocular morbidity followed by Vitamin A deficiency (33.4\%) and refractive error (23.7\%).

Conclusion: Data on ocular morbidity among Tribal school children is not readily available. Our study is one of the few studies to be conducted among the Tribal school children in rural area. A high prevalence of ocular morbidity among Tribal school children was observed. Since most of this morbidity is either preventable or treatable, school screening in tribal area forms an effective method to reduce this load.

Keywords: Tribal, School children, Ocular morbidity, Conjunctivitis, Refractive error.
\end{abstract}

\section{Introduction}

Vision is the most important special sense in human being. Normal vision is essential for normal physical, mental, psychological development and education. Early detection and treatment of ocular morbidity is an easy way to improve child health and development.
Mostly ocular morbidity originates in childhood and if undetected may result in severe ocular disabilities, in addition to affecting development, educational performance. ${ }^{1}$ Children in the schoolgoing age group (6-16 years) represent $25 \%$ of the population in the developing countries. ${ }^{2}$ 
There are an estimated 1.4 million blind children worldwide, $73 \%$ of whom live in low-income countries. ${ }^{3}$ An additional 7 million suffer from low vision, and another 10 million children have a correctable refractive error causing visual impairment, Visual acuity of <6/18). ${ }^{4}$ Estimated National Prevalence of Childhood Blindness/Low Vision is $0.80 / 1000$ in India. ${ }^{5}$ In children of age range $5-15$ years, the visual impairment is $6.4 \%$, with refractive errors as the major cause. ${ }^{6}$

The control of blindness in children is considered a high priority within the "WHO's Vision 2020 The Right to Sight Programme.", Many conditions associated with blindness lead to childhood mortality; hence, control of blindness in children is closely linked to child survival. ${ }^{8} \mathrm{~A}$ national survey on blindness 2001-02 showed that $7 \%$ of children aged 10-14 years have problems with their eye sight. A study conducted in the West Uttar Pradesh, it was found that the prevalence of ocular morbidity among school going children was $29.35 \%$. $^{9}$

Considering the fact that $30 \%$ of India's blind lose their sight before the age of 20 years, the importance of early detection and treatment of ocular morbidity and visual impairment in young children is obvious. ${ }^{10}$ Data on ocular morbidity among Tribal school children is not readily available. So, as an important public health topic, the present study was conducted (i) to estimate the prevalence of ocular morbidity among Tribal school children in Siliguri sub-division of Darjeeling district and (ii) to study the sociodemographic factors responsible for the causes of ocular morbidity in the Tribal school children.

\section{Materials and Methods}

This study was a school-based, observational study with cross-sectional study design carried out in 6 schools of Phansidewa \& Naxalbari Community Blocks of Siliguri sub-division, Darjeeling district in West Bengal, among 180 tribal school children belonging to the age group of 5 - 15 years from April 2018 to July 2018. Siliguri sub-division is situated at the foothills of the Himalayas. Tribal population of Phansidewa \& Naxalbari blocks constitute with $30.6 \%$ and $19.6 \%$ of the total population of blocks respectively (census 2011). Economy is mainly based on Tea garden \& agriculture. Major religion is Hindu; languages spoken are Hindi, Bengali and Sadri.

Sample size was calculated using formula for determination of sample size for estimating proportions, where:

Sample size $(\mathrm{N})=\mathrm{Z}^{2} \mathrm{PQ} / \mathrm{d}^{2}$ with a prevalence of 29.35\%, ${ }^{9}$ and 95\% Confidence Interval, Absolute error of $5 \%$ and adding $10 \%$ non-respondents, we got a minimum sample size of 180 .

Multistage random sampling technique was used. In the first stage, all the schools in Phansidewa \& Naxalbari blocks of Siliguri sub-division were enlisted; 6 schools out of them were selected randomly. In the next stage, all the tribal children aged $5-15$ years group of the respective schools were enlisted and 30 tribal children from each school were randomly selected.

\section{Data Collection}

The Headmasters of the selected schools were informed about the study and permission for the visit to the selected schools was sought personally. The Headmasters of the selected schools informed the parents of the students regarding the study and permission was taken and dates for examinations were fixed. The data collection instrument was a pretested semistructured questionnaire. It was pretested in randomly selected tribal school children which was not included in the study. Queries from children were asked in Hindi language, while information was filled in English language by the principal investigator. Examinations were done in the respective school campuses in clean, quiet and well-lit rooms. Only children present on the day of examinations were examined. Visual acuity (unaided) was assessed by using Snellen's chart, colour blindness was checked by using Ishihara's chart and torch examination of the eye was done. Visual acuity was measured using the Snellen's Visual acuity chart at 6 meter. Children with 
Visual acuity $<6 / 9$ underwent a pinhole vision to differentiate refractive errors from pathological conditions. Refractive error was diagnosed when a Visual acuity worse than 6/9 improved on pinhole test. Anterior segment examination including lids, lacrimal sac, conjunctiva, cornea, pupil, iris and lens were done using a torch light. A detailed anterior segment examination was done and children needing further assessment and management were referred to a higher centre.

\section{Data Analysis}

Collected data was checked for consistency and entered in Microsoft-Excel 2007 data sheet and it was analyzed by IBM Statistical Package for Social Sciences (SPSS) version 20. It was organized and presented using the principles of descriptive statistics. All analysis was done with the test of significance ( $P$ value, $c h i$-square).

\section{Result}

A total of 180 tribal students between aged 5-15 years were studied. Mean age of the study participants was $8.257 \pm 2.230$ years. In the present study $94(52.2 \%)$ were females and 86 $(47.8 \%)$ were males, $73(40.6 \%)$ were in $8-10$ years age group followed by $70(38.9 \%)$ were in age group $5-7$ years, majority 155 (86.1\%) were Hindu followed by 25 (13.9\%) were Christian, 97 (53.9\%) of respondents' father were illiterate and maximum 168 (93.3\%) of participants' father were tea garden labourer [Table 1].

Overall Prevalence of ocular morbidity among tribal school children of age 5-15 years was $51.7 \%$ [Table 2].

The commonest presenting symptoms were diminished vision $(33.3 \%$ ), followed by night blindness $(26.9 \%)$ and itching of eye $(25.8 \%)$ [Figure1].

Allergic conjunctivitis constitute (38.7\%) the major cause of ocular morbidity followed by Refractive errors (23.7\%), Bitot's spot (18.3\%), Conjunctival Xerosis $(9.7 \%)$, Corneal Xerosis $(5.4 \%)$ and others (4.3\%) [Figure2].

Prevalence of ocular morbidity more in the age group $8-10$ years $(22.8 \%)$, followed by
$5-7$ years age group (19.4\%) and in 11 years and above $(9.4 \%)$. and it was found to be not significantly different $(\chi 2=1.154, d f=2, p$ value $=0.652$ ). Similarly the prevalence of ocular morbidity was more among female children (30.0\%) compared to male children (21.7\%). However, it was found to be not significantly different $(\chi 2=2.632, d f=1, p$ value $=0.105)$ [Table $5]$.

Table-1: Socio-Demographic characteristics of children

\begin{tabular}{|l|c|c|}
\hline Characteristics & $\begin{array}{c}\text { Frequency } \\
\text { N=180 }\end{array}$ & $\%$ \\
\hline Age (In years) & 70 & 38.9 \\
\hline $5-7$ & 73 & 40.6 \\
\hline $8-10$ & 37 & 20.6 \\
\hline 11 \& above & Mean $=8.257$ & SD $=2.230$ \\
\hline Gender \\
\hline Male & 86 & 47.8 \\
\hline Female & 94 & 52.2 \\
\hline \multicolumn{3}{|c|}{} \\
\hline Hindu & 155 & 86.1 \\
\hline Christian & 13.9 \\
\hline Education level of Father & 25 & 53.9 \\
\hline Illiterate & 97 & 39.4 \\
\hline Primary School & 71 & 6.7 \\
\hline Secondary & 12 & 1.7 \\
\hline Occupation of Father & 3 & 5.0 \\
\hline Govt. Job & 9 & 93.3 \\
\hline Private Job \\
\hline Labourer (Tea Garden) & 168 \\
SD = Standard Deviation
\end{tabular}

Table-2: Prevalence of Ocular Morbidity

\begin{tabular}{|l|c|c|}
\hline Ocular Morbidity & $\begin{array}{c}\text { Frequency } \\
\mathbf{N = 1 8 0}\end{array}$ & $\boldsymbol{\%}$ \\
\hline Present & 93 & 51.7 \\
\hline Absent & 87 & 48.3 \\
\hline Total & $\mathbf{1 8 0}$ & $\mathbf{1 0 0}$ \\
\hline
\end{tabular}


Table-5: Distribution of children having ocular morbidities according to age \& gender

\begin{tabular}{|c|c|c|c|c|}
\hline \multirow[t]{2}{*}{ Age } & \multicolumn{2}{|c|}{$\begin{array}{c}\text { Ocular Morbidity } \\
\mathrm{N}=\mathbf{1 8 0}\end{array}$} & \multirow{2}{*}{$\begin{array}{c}\text { Total } \\
\text { N }(\%)\end{array}$} & \\
\hline & $\begin{array}{l}\text { Present } \\
\text { N }(\%)\end{array}$ & $\begin{array}{l}\text { Absent } \\
\mathbf{N}(\%)\end{array}$ & & \\
\hline $5-7 \mathrm{yrs}$ & 35 (19.5) & 35 (19.4) & $70(38.9)$ & $x^{2}=1.154$ \\
\hline $8-10 \mathrm{yrs}$ & $41(22.8)$ & $32(17.8)$ & $73(40.6)$ & $d f=2$ \\
\hline$\geq 11$ yrs & $17(9.4)$ & $20(11.1)$ & $37(20.5)$ & $p=>0.05$ \\
\hline Total & $93(51.7)$ & $87(48.3)$ & $180(100)$ & \\
\hline \multicolumn{5}{|l|}{ Gender } \\
\hline Male & 39 (21.7) & $47(26.1)$ & $86(47.8)$ & $x^{2}=2.632$ \\
\hline Female & $54(30.0)$ & $40(22.2)$ & $94(52.2)$ & $d f=1$ \\
\hline Total & $93(51.7)$ & $87(48.3)$ & $180(100)$ & $p=>0.05$ \\
\hline
\end{tabular}

Figure in parenthesis shows row percentage

Figure 1: Bar diagram shows distribution of children according to symptoms $(\mathrm{N}=93)$

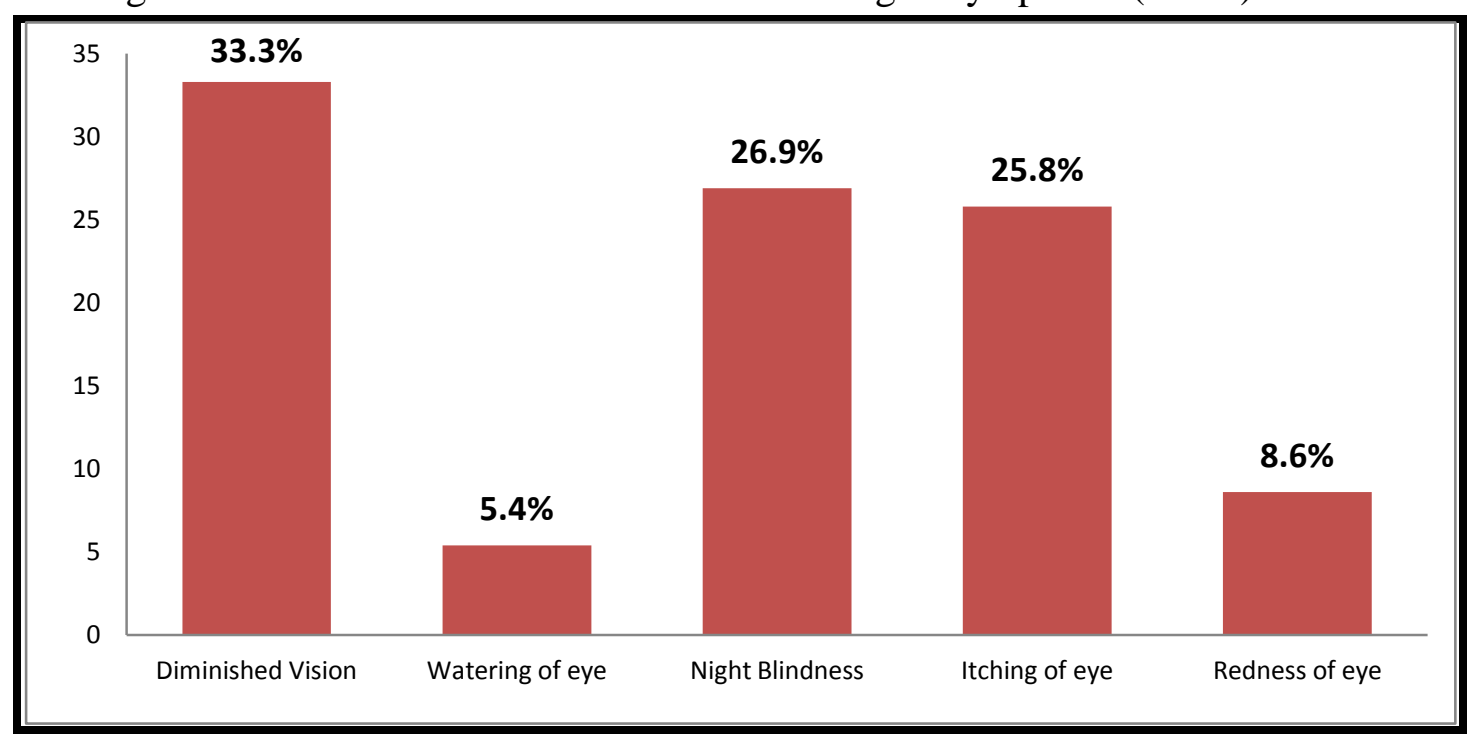

Figure 2: Pie chart shows distribution of children according to types of morbidity (N=93)

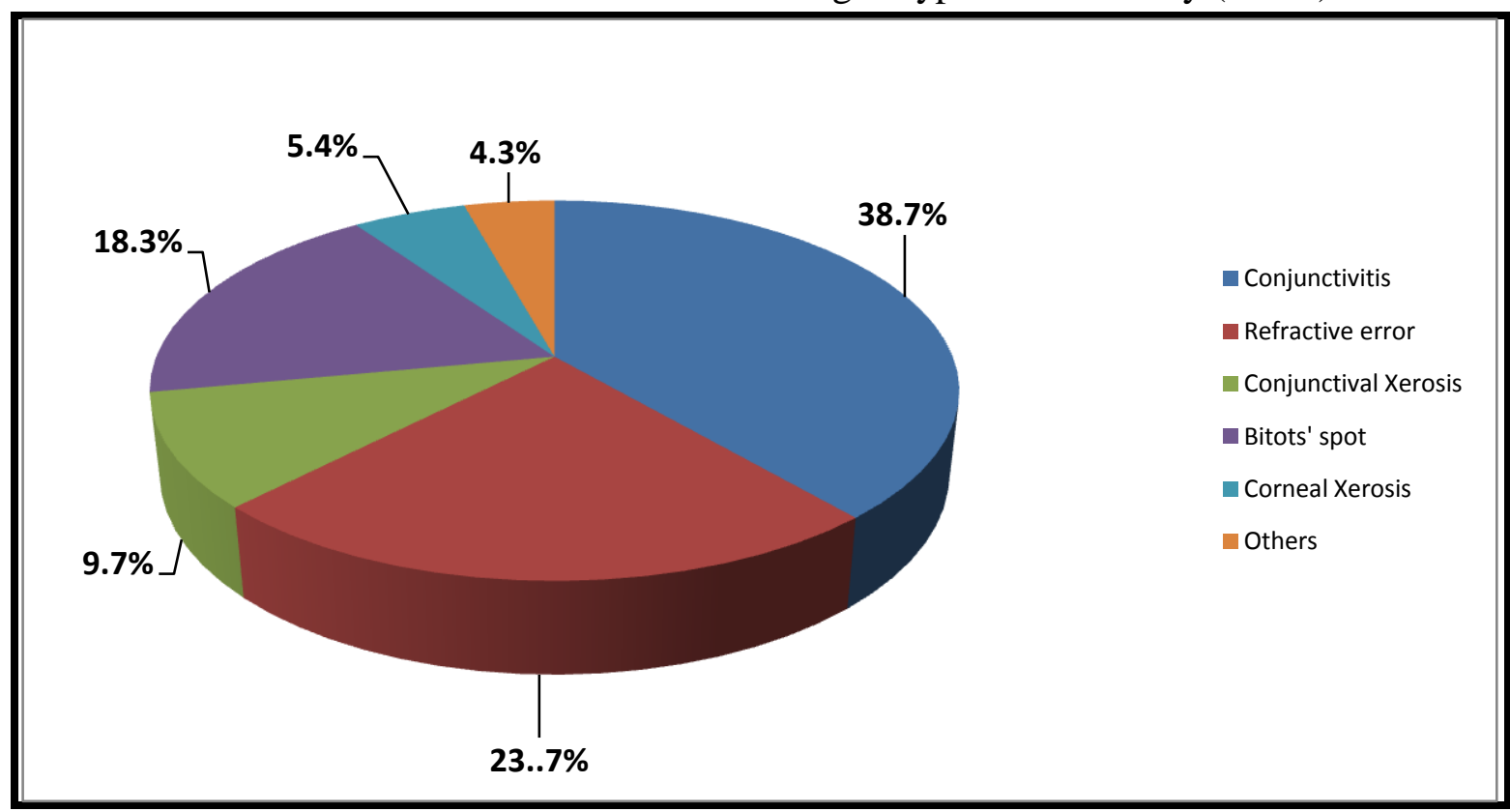

Others $=$ Anophthalmas, Congenital cataract 


\section{Discussion}

In the present study, a total of 180 Tribal school children aged 5 - 15 years group were examined. There were 86 males and 94 females. The overall Prevalence of ocular morbidity in this study was $51.7 \%$ with $21.7 \%$ in males and $30.0 \%$ in females. Similar, higher Prevalence of ocular morbidity has been reported from Haryana by Khurana et $a l^{11}$ (58.8\% in 4-18 years), from Rajasthan by Desai et $a l^{12}$ (71.7\% in 4-16 years) and from Hyderabad in South India by Kalikivayi et al $^{13}$ (43.5\% in $3-16$ years). The study conducted by Deshpande et $a l^{14}$, prevalence of ocular morbidities among school children in rural area of North Maharashtra in India showed $27.6 \%$. Similar study conducted by Neha et $a l^{15}$ in rural parts of central India, found a prevalence of $30.6 \%$. Study done by Kumar et $a l^{16}$, ocular morbidity amongst Primary School children in Delhi, prevalence was 22.7\%. Another study reported a prevalence of $26.5 \%$ among school children in north India. ${ }^{17}$ In a study from rural area of Tanzania, Africa, lower prevalence of $15.6 \%$ of ocular morbidity was reported in children aged 7-19 years. ${ }^{18}$ A study conducted by Naik et al in rural schools of Ahmednagar, Maharashtra, reported lower prevalence $10.5 \%$ of ocular morbidity among school children aged 6 15 years. ${ }^{19}$ Bansal et al also found the lower prevalence $13.3 \%$ among children aged 5-16 years in Kolar District in South India. ${ }^{20}$ Shrestha et al in their study in Nepal, found 19.6\% prevalence of ocular morbidity. ${ }^{21}$ A study by Ayanniyi et al prevalence of $19.9 \%$ ocular morbidity among primary school children in Ilorin, Nigeria. ${ }^{22}$

In the present study, Allergic conjunctivitis were found to be most important and accounted for $38.7 \%$ of total ocular morbidity followed by Vitamin A deficiency $33.4 \%$ which included Bitot's Spots (18.3\%) and Conjunctival Xerosis $(9.7 \%)$ and Corneal Xerosis (5.4\%). Refractive error accounted for $23.7 \%$ of total ocular morbidity. Neha et al found higher refractive error which accounted for $50.5 \%$ of total ocular morbidity followed by Vitamin A deficiency which included Bitot's Spots (21.2\%) and Conjunctival Xerosis (11.1\%). ${ }^{15}$ Deshpande et al also found that the main causes were refractory errors $(36.6 \%)$, Vitamin A deficiency (25.6\%) which are treatable. ${ }^{14}$ Bansal et al reported higher prevalence of refractive error $89.5 \%$ followed by Conjunctivitis $5.9 \%$ and Vitamin A deficiency $5.6 \% .^{20}$ Naik R et al found very low prevalence of refractive error and Vitamin A deficiency. ${ }^{19}$ Kumar et al also found that the major morbidity was refractive errors. ${ }^{16}$ Gupta $e t a l^{23}$, Das et $a l^{24}$ in Kolkata and Desai et $a l^{12}$ in Jodhpur also reported a similar prevalence of refractive errors $22 \%$, $25.1 \%$ and $20.8 \%$, respectively. International studies conducted by Shrestha et al reported a similar prevalence of refractive error $21.9 \% .{ }^{21} \mathrm{Lu}$ et al also found a comparable refractive error prevalence of $11.07 \%$ in China. ${ }^{25}$ However, low prevalence of refractive errors of $2 \%$ has been reported from Eastern India by Datta et al among primary school children of 5-13 years. ${ }^{26}$

Thus the results are relevant with other studies but Prevalence of ocular morbidity among Tribal school children is far more as compared to other studies. Hence, need of intervention is emphasized.

Strength of the study lies in the fact that early detection of treatable causes of ocular morbidity will help in child health development. Also, the fact that parents are being counselled will help in penetrating the thought better in the society.

The limitation of the study is due to the site, children were examined at rural schools hence thorough examination was not possible.

\section{Conclusion}

It was concluded that high prevalence of ocular morbidity among Tribal school children was observed in rural area of Siliguri Sub-Division. Allergic conjunctivitis, Vitamin A deficiency and refractive errors were the most common ocular disorders. Prevention, early recognition and prompt treatment of ocular diseases by regular screening of students would definitely reduce ocular morbidity, so that they can attain their full 
potential in the course of their education. There is a need to educate people collectively through health facilities, media, government and nongovernmental organizations with emphasis on the importance of ocular health.

\section{Acknowledgment}

We are thankful to all the study school Headmasters for allowing us to carry out this study in their respective compounds.

\section{Sources of support in the form of grants: Nil}

\section{Reference}

1. World Health Organization (1999) Report of WHO/IAPB scientific meeting, Hyderabad, India 13- 17, April. Childhood Blindness Prevention. WHO/PBL/87 3. Murthy GVS.

2. Sharma PM: School eye health - much more than vision screening. School health in India, e-magazine from SHARP NGO. 2008; Vol. 10, Jul. - Sept.

3. World Health Organization, Preventing Blindness in Children. Report of a WHO/IAPB Scientific Meeting, Hyderabad, India, 1999.WHO/PBL/00.77.Geneva:World

Health Organization; 2000. Available fromhttp://www.apps.who.int/iris/bitstrea m/10665/66663/1/WHO_PBL_00.77.pdf. [Last accessed on 2018 Aug 16].

4. Jose R, Sachdeva S. School eye screening and the National Program for Control of Blindness. Indian Pediatr 2009; 46:205-8.

5. Jose R. Present status of the national programme for control of blindness in India. Community Eye Health J 2008; 21:103-4.

6. Kishore J. National Health Programmes of India. 9th ed. New Delhi: Century Publications; 2011. p. 420-1.

7. World Health Organization. Global Initiative for the Elimination of Avoidable Blindness. WHO/PBL/97.61. Geneva,
Switzerland: World Health Organization; 1997.

8. Gilbert C, Foster A. Childhood blindness in the context of VISION 2020 - The right to sight. Bull World Health Organ 2001; 79:227-32.

9. Singh V, Malik KP, Malik VK, Jain K. Prevalence of ocular morbidity in school going children in West Uttar Pradesh. Indian J Ophthalmol 2017; 65:500-8.

10. Bhalerao SA, Tandon M, Singh S, Dwivedi S, Kumar S, Rana J. Visual impairment and blindness among the students of blind schools in Allahabad and its vicinity: A causal assessment. Indian J Ophthalmol 2015; 63:254-8.

11. Khurana AK, Sikka KL, Parmar IPS, Aggarwal SK; Ocular morbidity among school children in Rohtak city. Indian J Public Health, 1984; 28:217-220.

12. Desai S, Desai R, Desai NC, Lohiya S, Bhargava G, Kumar K; School eye health appraisal. Indian J Ophthalmol. 1989; 37: 173-175.

13. Kalikivayi V, Naduvilath TJ, Bansal AK, Dandona L; Visual impairment in school children in Southern India. Indian $\mathbf{J}$ Ophthalmol., 1997; 45: 129-134.

14. Deshpande JD, Malathi K. Prevalence of ocular morbidities among school children in rural area of north Maharashtra in India, National Journal of Community Medicine 2011; 2 (2):249-254.

15. Kotwal NN, Nikose A. Study of visual morbidity among the school going children in rural part of Central India International Journal of Biomedical and Advance Research 2016; 7(5): 219-222.

16. Kumar R, Dabas P. Ocular Morbidity amongst Primary School Children in Delhi, Health and Population. Perspectives and Issues 2007; 30 (3): 222-229.

17. Rao SM, Gulati PV and Patnaik KC. (1972) Chronic Defects among Urban School Children, IJPH, XVI (1): 21. 
18. Wedner SH, Ross DA, Balira R, Kaji L, Foster A. Prevalence of eye diseases in primary school children in a rural area of Tanzania. Br J Ophthalmol. 2000; 84:1291- 7

19. Naik R, Gandhi J, Shah N. Prevalence of Ocular Morbidity among School Going Children (6-15years). Sch. J. App. Med. Sci., 2013; 1(6):848-851

20. Bansal Amol, Kanthamani Krishnappa et al, Ocular Morbidity in School going Children of Kolar District, South India, $J$ Clin Biomed Sci 2012; 2(4):175-184.

21. Shrestha RK, Joshi MR et al, Ocular Morbidity among Children Attending Government and Private Schools of Kathmandu Valley, J Nepal Med Assoc 2011; 51 (184): 182-88.

22. Ayanniyi A, Mahmoud AO, Olatunji FO, Causes and prevalence of Ocular Morbidity Among Primary School Children in Ilorin, Nigeria, Niger J Clin Pract. 2010 Sep; 13(3): 248-53.

23. Gupta M, Gupta BP, Chauhan A, Bhardwaj A. Ocular morbidity prevalence among school children in Shimla, Himachal, North India. Indian J Ophthalmol 2009; 57:133-8.

24. Das A, Dutta H, Bhaduri G, De Sarkar A, Sarkar K, Bannerjee M. A study on refractive errors among school children in Kolkata.J Indian Med Assoc 2007; 105:169-72.

25. Lu P, Chen X, Zhang W, Chen S, Shu L. Prevalence of ocular disease in Tibetan primary school children. Can J Ophthalmol 2008; 43:95-9.

26. Datta A, Choudhury N, Kundu K. An epidemiological study of ocular condition among school children of Calcutta Corporation. Indian J Ophthalmol 1983; 31:505-10. 